\title{
Erratum
}

\section{A comprehensive compilation of 1001 nucleotide sequences coding for proteins from the yeast Saccharomyces cerevisiae $(=$ ListA2)}

\author{
Marie-Odile Mossé ${ }^{1}$, Patrick Linder ${ }^{2}$, Jaga Lazowska ${ }^{1}$, and Piotr P. Slonimski ${ }^{1}$ \\ 1 Centre de Génétique Moléculaire, Laboratoire propre dı CNRS associé à l-Université Pierre et Marie Curie, \\ F-91190 Gif-sur Yvette, France \\ ${ }^{2}$ Department of Microbiology, Biozentrum, 70 Klingelbergstrasse, $\mathrm{CH}-4056$ Basel, Switzerland
}

Received April 22, 1992

In the list starting on page 70 of Volume 23 there were unfortunately various errors. The lines concerned are printed below with the corrections.

Presentation of ListA2

\begin{tabular}{|c|c|c|c|c|c|c|c|}
\hline & Gene & Synonym & Mnemonic & Length & $\begin{array}{l}\text { Codon } \\
\text { bias }\end{array}$ & Reference & $\begin{array}{l}\text { Accession } \\
\text { number }\end{array}$ \\
\hline 44 & ALG1 & & SCALG1 & 1347 & 0.063 & J. BIOL. CHEM. 265: 7042-7049 (1990). & $\mathrm{J} 05416$ \\
\hline 63 & $\mathrm{ARG} 3$ & & SCARG30T & 1014 & 0.181 & EUR. J. BIOCHEM. 166:371-377 (1987). & M28301 \\
\hline 106 & CAT3 & SNF4 & SCSNF4 & 966 & 0.164 & MOL. CELL. BIOL. 9:5045-5054 (1989). & M30470 \\
\hline 140 & CDC6 & & SCCDC601 & 1539 & 0.114 & MOL. CELL. BIOL. 0:0-0 (0). & $\mathrm{M} 22858$ \\
\hline 149 & $\mathrm{CHCl}$ & & SCCHC1 & 4959 & 0.313 & J. CELL. BIOL. 112:65-80 (1991). & $\mathrm{X} 52900$ \\
\hline 150 & CHL1 & & SCCHL1 & 2583 & -0.025 & EMBO J 9:4347-4358 (1990). & $X 56584$ \\
\hline 151 & $\mathrm{CHO} 1$ & PSS & SCPSSG & 828 & 0.170 & EUR. J. BIOCHEM. 167:7-12 (1987). & X05944 \\
\hline 158 & CIT2* & & SCCIT2A & 72 & -0.104 & MOL. CELL BIOL. 11:38-46 (1991). & M54982 \\
\hline 166 & CLC1 & & SCCLC1 & 699 & 0.199 & J. CELL. BIOL. 111:1437-1449 (1990). & $\times 52272$ \\
\hline 196 & CPS1 & & SCCPS1 & 1728 & 0.310 & EUR. J. BIOCHEM. 197:399-405 (1991). & $\times 57316$ \\
\hline 197 & CPT1 & & SCCPT1 & 1221 & 0.098 & J. BIOL. CHEM. 265: 1755-1764 (1990). & J05203 \\
\hline 201 & CTK1 & & SCCTK1A & 1581 & 0.001 & GENE EXPRESSION 1:149-167 (1991). & M69024 \\
\hline 202 & CTR1 & & SCCTR & 1689 & 0.282 & J. BIOL. CHEM. 265: 15996-16003 (1990). & $\mathrm{J} 05603$ \\
\hline 203 & CTT1 & & SCCTT1 & 1686 & 0.312 & EURO. J. BIOCHEM. 160:487-490 (1986). & $\mathrm{X} 04625$ \\
\hline 206 & CYC1 & & SCCYT1 & 327 & 0.467 & CELL 16:753-761 (1979). & $\mathrm{X} 03472$ \\
\hline 255 & ERG11 & & SCCYLDA & 1590 & 0.638 & BBRC 155:317-323 (1988) & M21483 \\
\hline 256 & ERG8 & & SCERG8 & 1272 & 0.051 & MOL. CELL. BIOL. 11:620-631 (1991). & M63648 \\
\hline 268 & FBP1 & & SCFBP1 & 1044 & 0.259 & FEBS LETT. $236: 195-200(1988)$ & Y00754 \\
\hline 326 & HAP2 & & SCHAP2 & 795 & 0,055 & MOL. CELL. BIOL. $7: 578-585$ (1987). & M15243 \\
\hline 337 & $\mathrm{HHF} 2$ & $\mathrm{H} 4, \mathrm{H} 4 \mathrm{II}$ & $\mathrm{SCH} 4$ & 309 & 0.771 & NUCLEIC ACIDS RES. 11:5347-5360 (1983). & $\mathrm{K} 03154$ \\
\hline 360 & HSP70 & & SCILSI-1 & 153 & 0.128 & NUCLEIC ACIDS RES. 15:99-106 (1989). & $\mathrm{X} 07886$ \\
\hline 377 & ILS1 & & SCILSI-2 & 3216 & 0.407 & NUCLEIC ACIDS RES. 15:99-106 (1989). & $\mathrm{X} 07886$ \\
\hline 384 & IMP2 & & CGM0300 & 936 & 0.139 & YEAST 8: 83-92 (1992). & X61928 \\
\hline 506 & NAP1 & & SCNAPI & 1251 & 0.180 & J. BIOL. CHEM. 266: $7025-7029$ (1991). & M63555 \\
\hline 548 & PEP4 & & SCPEP4 & 1215 & 0.467 & MOL. CELL. BIOL. 6:2500-2510 (1986). & M13358 \\
\hline 551 & PET3 & & SCPET3 & 2154 & 0.002 & MOL CELL. BIOL. $7: 2728-2734$ (1987). & M17143 \\
\hline 590 & PPA1 & & SCPPA1 & 639 & 0.412 & BBRC 168:574-579 (1990). & M35294 \\
\hline 620 & PSE1 & & SCPSEIG & 3267 & 0.172 & J. CELL. SCI. 101: $709-719(1992)$ & Z11538 \\
\hline 623 & PUT1 & & SCPUT1 & 1428 & 0.243 & MOL. CELL. BIOL. 7:4431-4440 (1987). & M18107 \\
\hline 660 & RAS2 & & SCRASH02 & 966 & 0.218 & NUCLEIC ACIDS RES. 12:3611-3618 (1984). & $\mathrm{X} 00528$ \\
\hline 663 & $\mathrm{REC102}$ & & SCREC102 & 600 & -0.004 & MOL. CELL. BIOL. 12:1248-1256 (1992). & M74045 \\
\hline 687 & RP29 & & SCRP29 & 465 & 0.827 & J. BIOL. CHEM. 259:9218-9224 (1984). & $\mathrm{K} 02650$ \\
\hline 689 & RP51B & & SCRP51B & 408 & 0.832 & MOL. CELL. BIOL. 4:1871-1879 (1984). & $\mathrm{K} 02480$ \\
\hline 784 & SKI3 & & CGM0219 & 4296 & 0.061 & YEAST 5: $149-158(1989)$ & \\
\hline 796 & SNF2 & & SCSNF2A & 5109 & 0.112 & PNAS 88: 2687 -2691 (1991). & M61703 \\
\hline 803 & SPA2 & & SCSPA2G & 4398 & 0.090 & J. CELL. BIOL. 111;1451-1464 (1990). & $\times 53731$ \\
\hline 855 & STE50 & & SC5 & 1038 & 0.110 & YEAST $0: 0-0(0)$ & $\mathrm{Z} 11116$ \\
\hline 862 & SUC2 & & SCINVE & 1596 & 0.425 & MOL. CELL. BIOL. 3:439-447 (1983). & V01311 \\
\hline 877 & SWI6 & & SCSW16 & 2409 & 0.010 & NATURE 329: 651 (1987). & $\mathrm{X} 06238$ \\
\hline 898 & TIF1 & & SCTIF1 & 1185 & 0.834 & NUCLEIC ACIDS RES. 16:10359-10359 (1988). & $\mathrm{X} 12813$ \\
\hline 903 & TIF51A & & SCTIF51A & 471 & 0.908 & MOL. CELL. BIOL. 11:3105-3114 & M63541 \\
\hline 912 & TPK1 & PK25 & SCPK 25 & 1191 & 0.200 & J. BIOL. CHEM. 262:2549-2553 (1987). & $\mathrm{J} 02665$ \\
\hline 944 & UBC1 & & SCUBC1G & 645 & 0.117 & EMBO J. 9:4535-4541 (1990). & $\mathrm{X} 56402$ \\
\hline 967 & URA6 & & SCUMPK & 612 & 0.230 & BBRC 165: 464-473(1989). & M31455 \\
\hline 983 & YAP3 & & CGM0297 & 1707 & 0.171 & YEAST 6:127-137 (1990). & IVISI+J \\
\hline
\end{tabular}

